Portland State University

PDXScholar

\title{
Informing Subterranean Transit Station Design from Existing and Future Station Typologies; an Informative Exploration of how to Develop Underground Station Design for MAX Light Rail
}

Antonio P. Ramos-Crosier

Portland State University

Follow this and additional works at: https://pdxscholar.library.pdx.edu/honorstheses Let us know how access to this document benefits you.

\section{Recommended Citation}

Ramos-Crosier, Antonio P., "Informing Subterranean Transit Station Design from Existing and Future Station Typologies; an Informative Exploration of how to Develop Underground Station Design for MAX Light Rail" (2019). University Honors Theses. Paper 797.

https://doi.org/10.15760/honors.815

This Thesis is brought to you for free and open access. It has been accepted for inclusion in University Honors Theses by an authorized administrator of PDXScholar. Please contact us if we can make this document more accessible: pdxscholar@pdx.edu. 
Informing Subterranean Transit Station Design from Existing and Future Station Typologies; an Informative Exploration of how to Develop Underground Station Design for MAX Light Rail

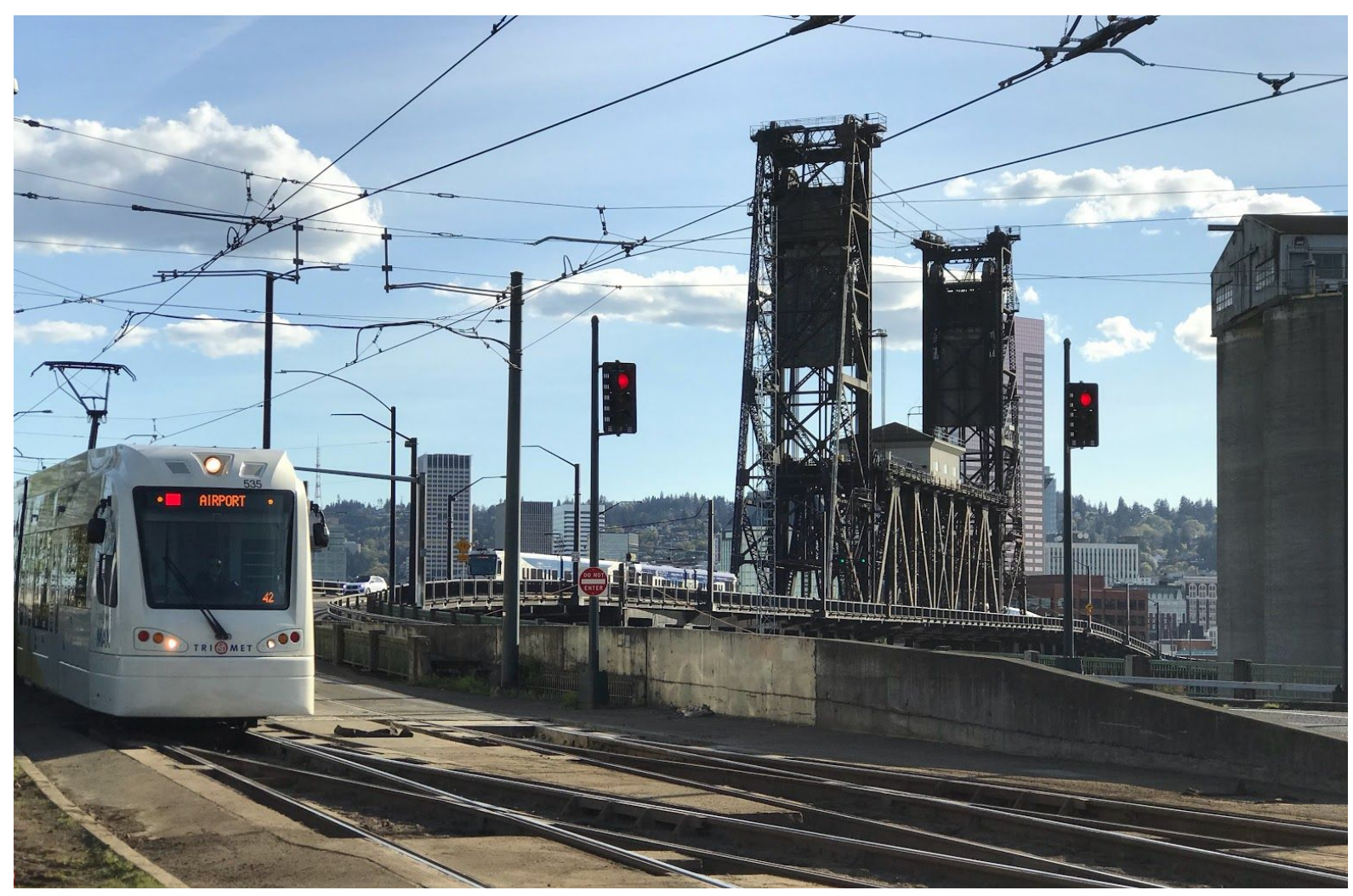

Image 1: MAX Red line crossing the Steel Bridge, which is a key piece of infrastructure that the regional connector aims to avoid with the implementation of a new tunnel. Image taken by Antonio Crosier.

By: Antonio Ramos-Crosier

Advisor: Jeff Schnabel 
Research Question: In anticipation of TriMet and the City of Portland's vision to create the subterranean tunnel for MAX light trail beneath downtown, which design considerations must be made in order to ensure that MAX light rail will continue to promote downtown walkability, passenger comfort, and economic vitality?

\section{Background:}

The City of Portland's Enhanced Transit Corridor Plan, which aims at improving TriMet's overall public transit speed and system efficiency, has identified a proposal to create a subterranean transitway for MAX light rail from the Lloyd District, to Goose Hollow as a way to speed trains through downtown Portland. The objective of this project, which is set to be open as soon as 2035 , is intended to create more reliable train service that will bypass a seismically deficient steel bridge crossing. It is also intended as a bypass for the traffic ridden streets in Portland's city center. The new East-West tunnel has been poised as the solution for many of these conflicts. Although vaguely labeled as the Regional Connector Transit Tunnel, the project will at the very least, include tunneled access for MAX light rail under downtown Portland along a yet to be determined route. Even though TriMet does have one existing underground station located at Washington Park, this station primarily serves people who are visiting the parks tourist attractions instead of everyday commuters. This means that TriMet has yet to design an underground stations for its core commuter types.

TriMet does have an existing design criteria for both its bus and railway design, however these design criteria serve the systems 96 surface running stations (plus the aforementioned Washington Park station), and will apply to the future 13 surface 
running stations that will be built for the Southwest Corridor Light Rail Project. The planning for the Regional Connector tunnel has only advanced through the "black-lined" route planning that has been conducted by the agency in recent months, "black lining" refers to the conceptual rail alignments that the agency has proposed.

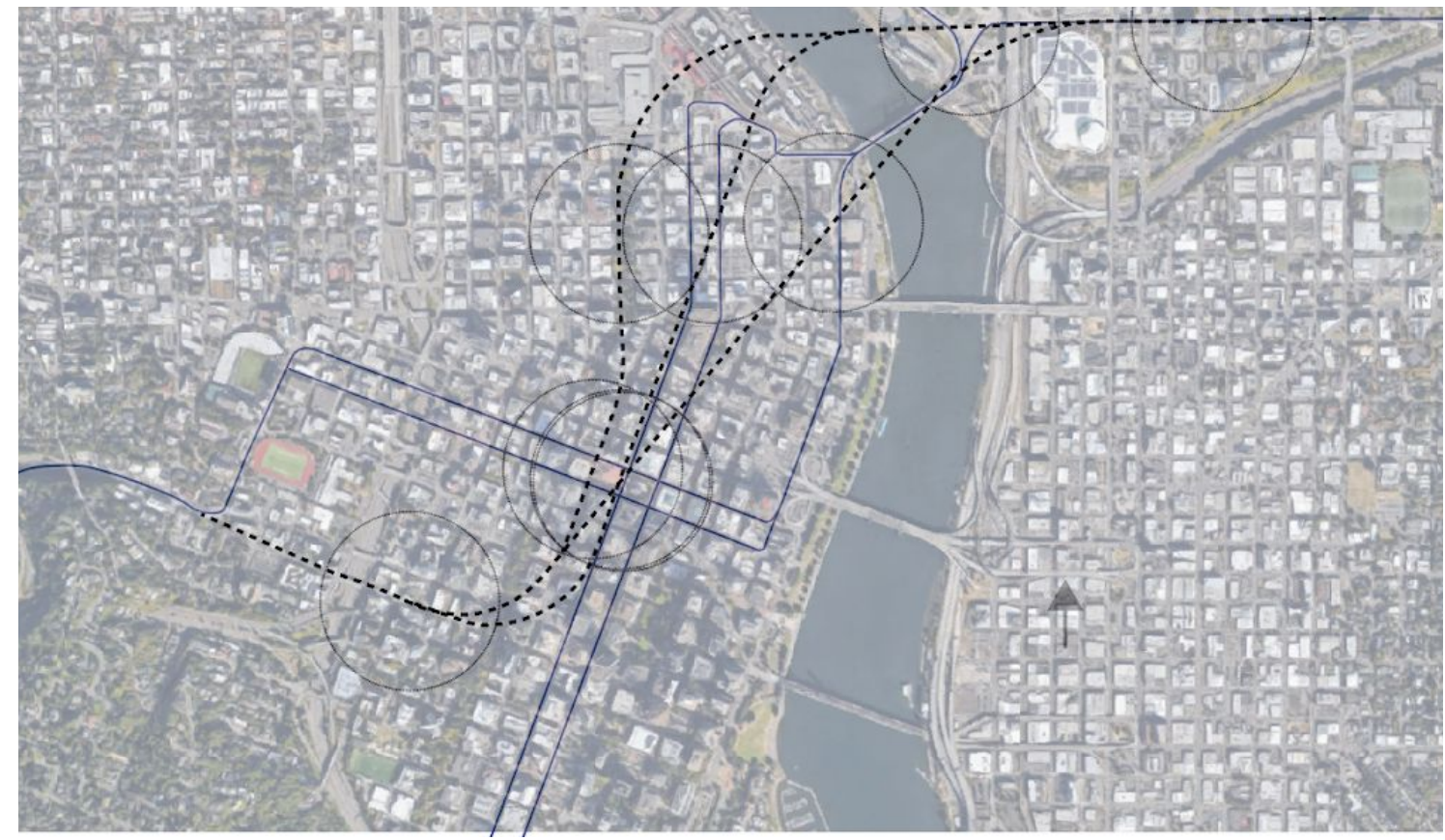

Image 2: Potential light rail alignments for the regional connector tunnel, and their potential station locations. Content provided by TriMet.

\section{Existing Light Rail Station Conditions:}

TriMet operates a rail system that is comprised of 97 stations over 5 light-rail lines that provide connections to various centers around the region. Each of these lines either crosses through or terminates in downtown Portland, where each line snakes through the urban core of city through right-of-ways in city streets. The downtown portion of the system is fully integrated into the urban layout of the city streets, as platforms blend into city sidewalks and urban park spaces. This trolley like transit 
approach for the MAX system has contributed to several success' in the continued revitalization of the city center, as the stations accessible fronts help to create a more active streetscape.

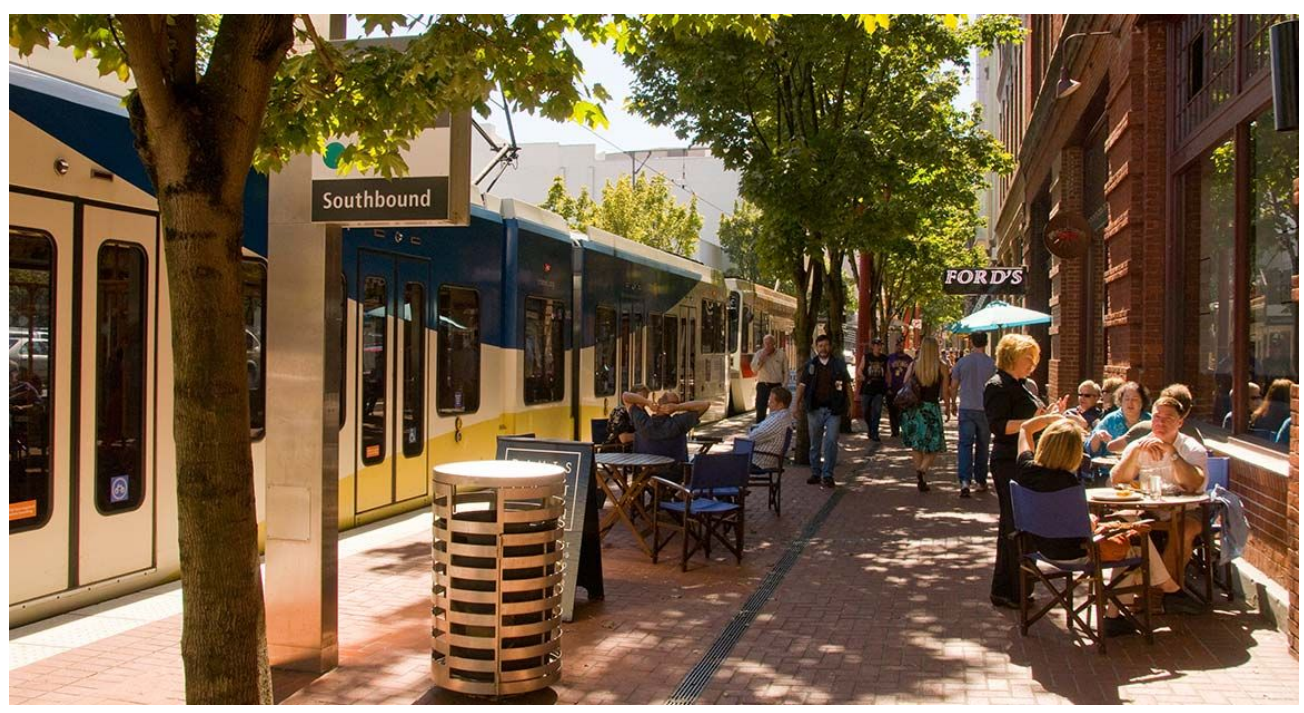

Image 3: A MAX station in Northwest Portland, which highlights the blurring of station and public right of ways. Image source, OregonLive.

The existing station typology in Portland's city center is comprised of side running platforms that exist at the edge of enlarged sidewalks. The platforms are approximately 200 feet long, which is the typical length of a city block. This allows for TriMet to operate a maximum of two-combined light rail cars at any given time across its entire system. Station amenities include seating, covered waiting canopies, ticketing information and machines, wayfinding information, and station signage. A substantial portion of this content has been modularized and repeated in stations across the system and City Center. 


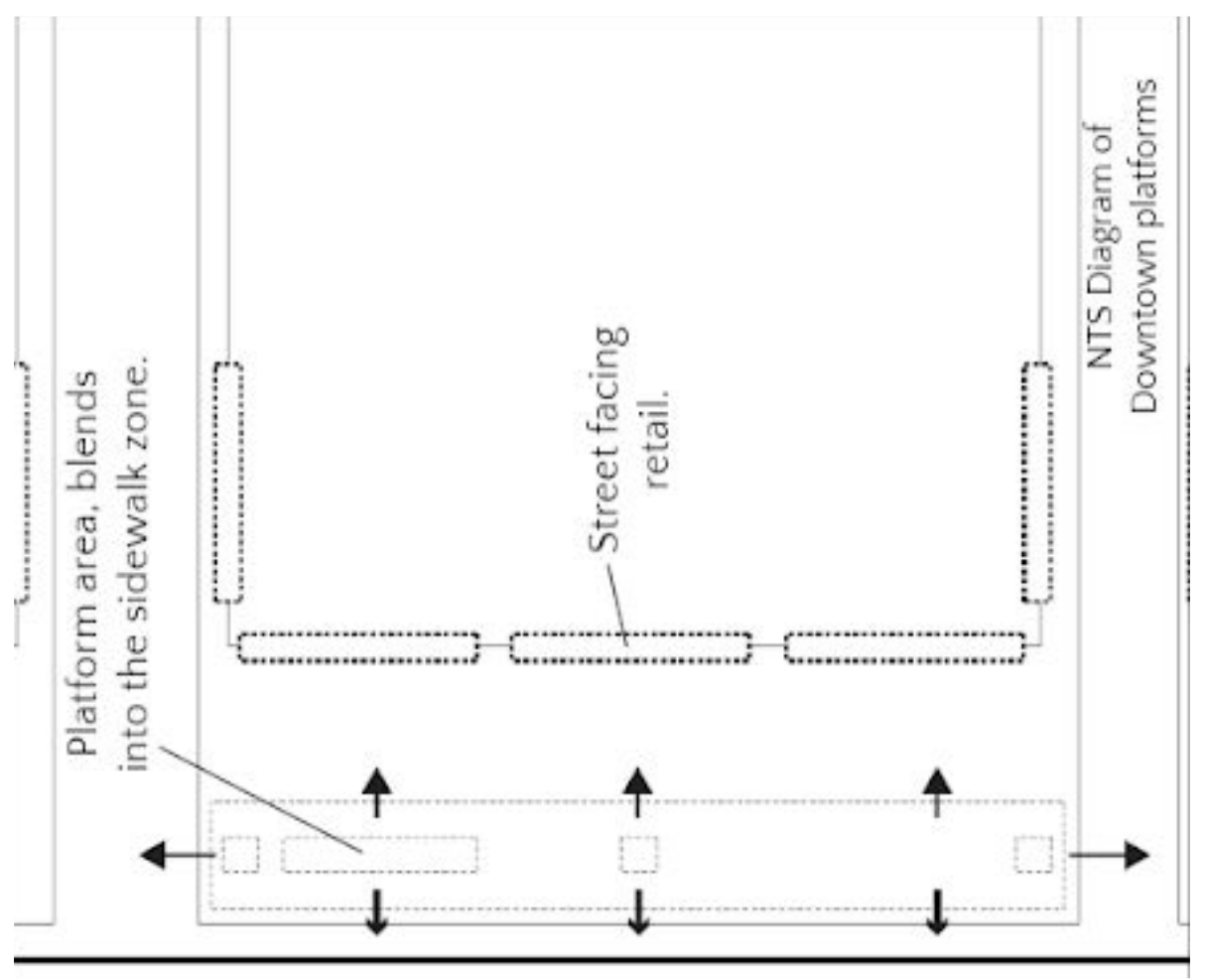

Image 4: Not to scale diagram of the light rail platforms relationship to the urban layout of the streetscape. Diagram produced by Antonio Crosier.

In all, TriMet has played a key role in the methods in which urban design has progressed the impact of methodical inclusive designs that extend beyond the use of its transit riders

\section{Challenges for Subterranean Stations in Portland:}

Given light rail's important impact on the streetscape of Portland's city center, it is difficult to imagine that a substantial if not the entirety of the system will be encased under the streets of the city. The first impact that will be noticeable from the move into an underground system will be the absence of high capacity stations that will directly sit adjacent to active storefronts and park spaces. As trains shift into underground spaces, the public's ability to visualize light rail as a viable transportation method will also be 
downplayed as the trains themselves will no longer be visibly present along city streets.

Other transit alternatives such as surface running streetcars and buses will still be running in the surface street however.

An additional challenge for subterraneas stations will be the new design typologies that will have to grow out of the new underground station design. Now, the traditional methods of station amenities and the stations direct influence on its relationship from platform to street level will result in contrasting methods of design that TriMet has not faced before. Which are a detachment from the streetscape, and the implementation of more controlled station environments that would require more significant isolation from the urban design of the city streets.

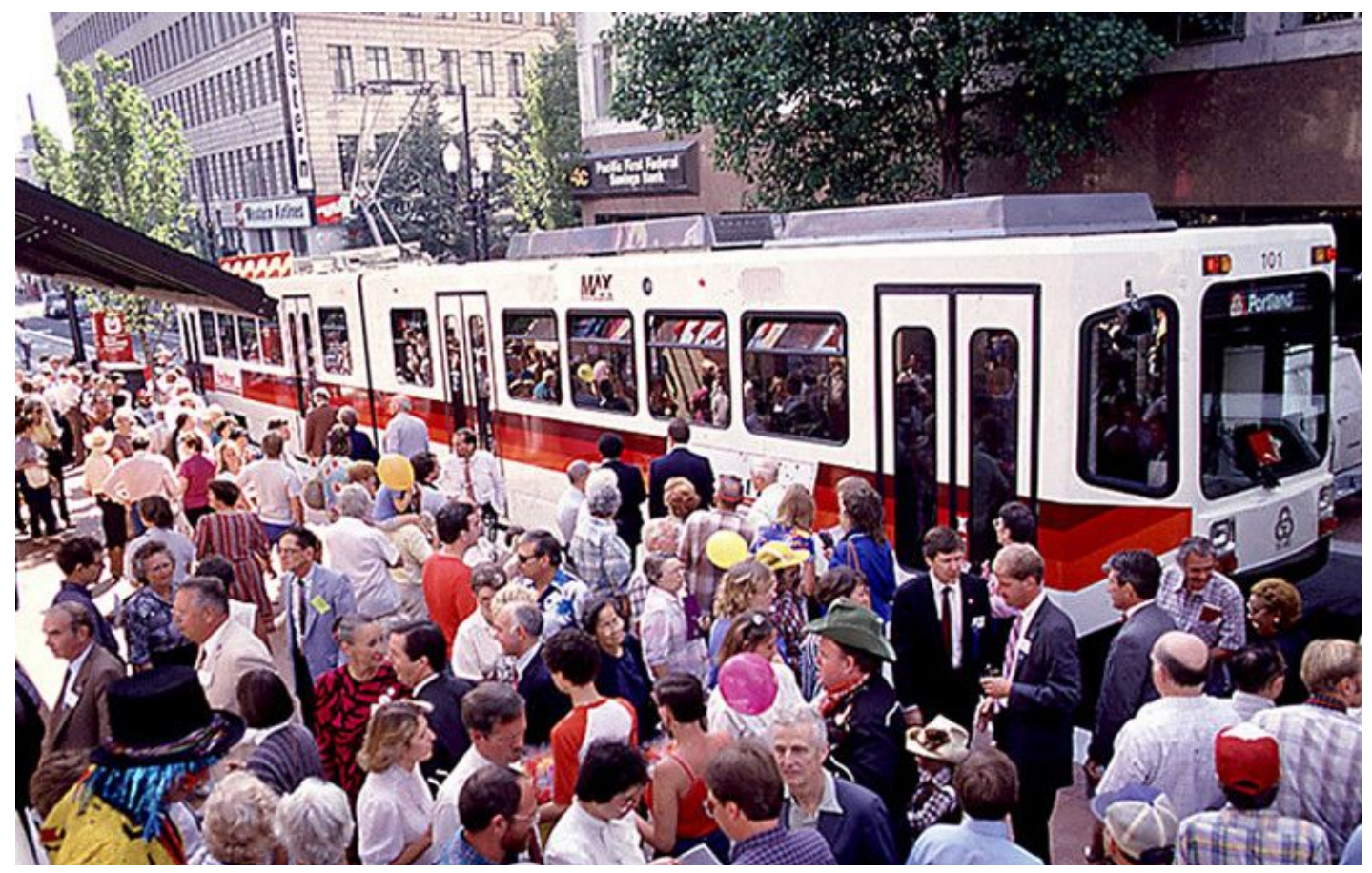

Image 5: A MAX light rail vehicle at the Pioneer Square Station during the opening of the Eastside MAX in 1986. This graphic is significant in that it shows how light rail ignated a new relationship with the urban design of the city, as the platforms began to provide more energy to a growing city center. Image source, TriMet. 


\section{Modern Subway Design precedents:}

\section{Seattle (Sound Transit):}

The Seattle region several transit agencies that operates rail transit in the region, the two most utilized agencies being King County Metro, which operates two surface running streetcar lines; and Sound Transit which runs light rail and commuter rail lines within the greater Seattle metropolitan area. For this observation, I will be dissecting the Link Light Rail system which operates in Seattle. This section will cover Existing, under construction, and planned underground light rail platforms that connect with the city of Seattle. These will include; the Downtown Seattle Transit Tunnel, the University Link Extension, the Northgate Extension, and the Eastlink extension designs.

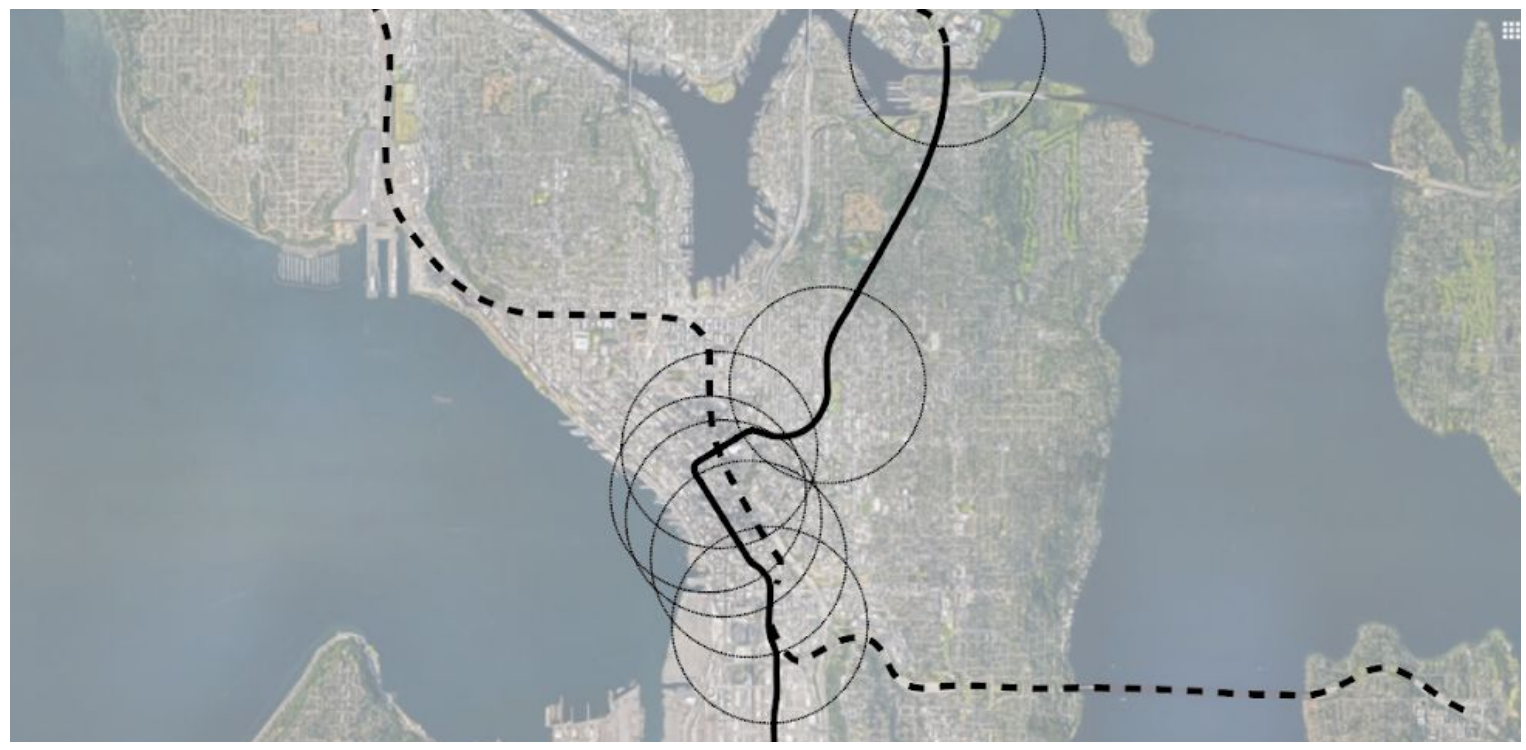

Image 6: an existing (solid), and planned or under construction (dashed) map of the Sound Transit Link Light Rail system that I observed for this section of the study. The stations I have chosen are circled with dashed lines.

\section{The Downtown Seattle Transit Tunnel:}

This is a 1.3 mile tunnel comprised of 4 subterranean stations. The tunnel was opened in 1990 and was only serviced by buses until the tunnel had proper light rail tracks 
installed for link light rail central link line in 2009. As of 2019, the subterranean stations are now only served by light rail, due to bus stops being moved to surface streets. These were the first series of underground stations that were built in the city of Seattle, however it is unique that the stations were first built for bus operations under the presumption that light rail would eventually utilize these tunnels, only for bus operations to cease usage in the tunnel after Sound Transit and King County Metro swapped ownership of the tunnels in 2019.

The station design for all four of these stations follows common design elements which contain small variations in program placement in respect to the surrounding context of the station portal area. The station entry for this section of light rail is comprised of roughly $10-15$ feet wide gaps that have the station name placed above it. These lead into sharp turns that direct passengers down a series of escalators and stairs that lead into the ticketing hall which is underground. The ticketing hall for these stations has scattered information displays and ticketing machines that are placed along the edges of various spacious and open level that lead to various other station entry points, which lead to access points that lead down to the platforms themselves.

The stations have elements that are not in line with Sound Transit's current design practices for stations built and planned after the introduction of light rail into the Seattle Transit Tunnel. These features include station entrances that are contextual and dynamisized for its surrounding neighborhood. 


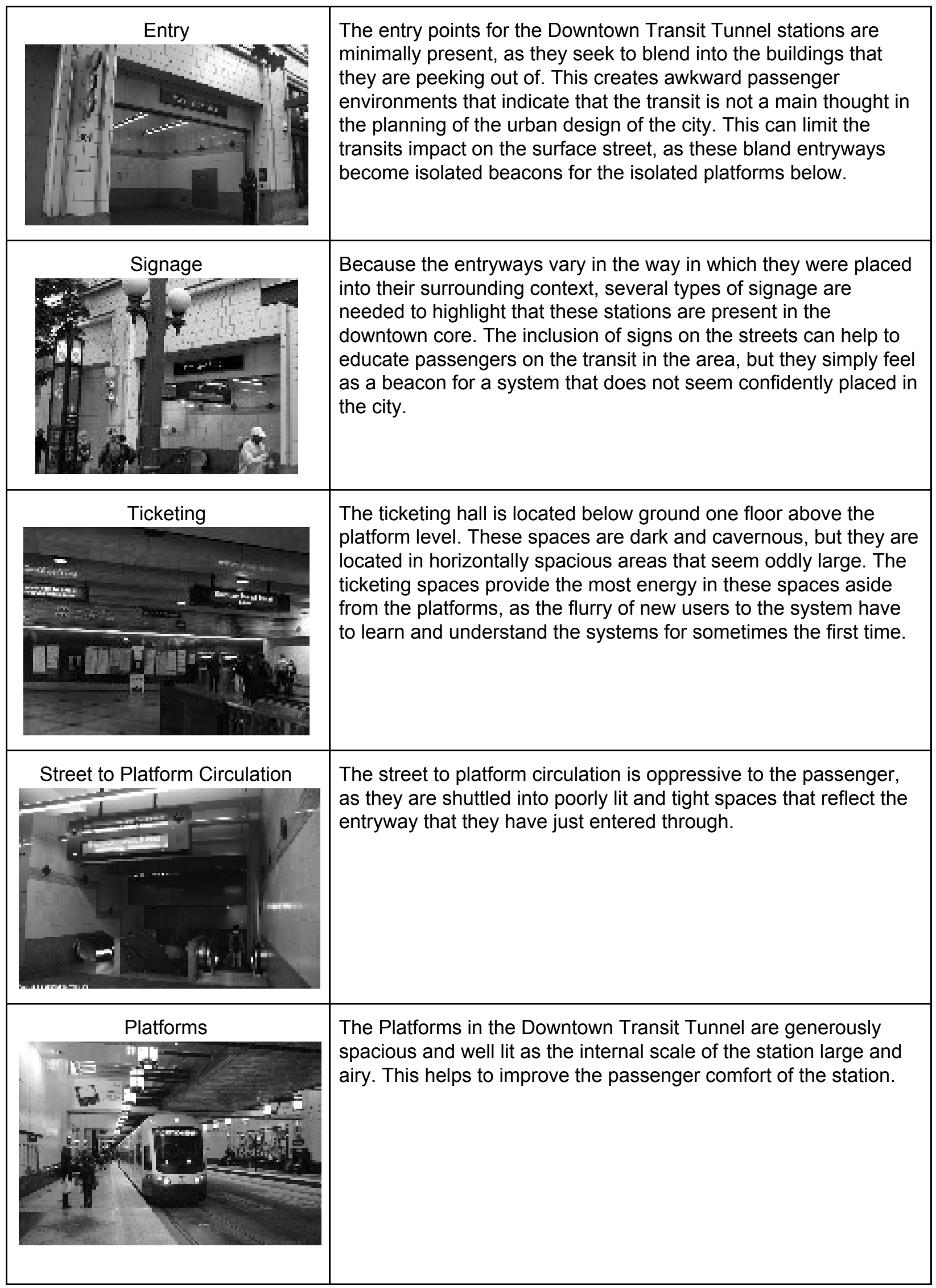




\section{Capitol Hill Station:}

The Capitol Hill station for Link Light rail was opened in 2016, as one of two stations built for the University Link project. The station was built at the neighborhoods most central intersection of E John and Broadway Street. The station has three entry points which descend downward into a center running platform. The entry points in the station use 2 dimensional mosaic murals to lead passengers down into the mezzanine which leads down into the platform.

At the platform level, the station provides generous ceiling height that shows the exposed interior structure and a permanent art installation. The platform also has minimal obstructions and furniture pieces. Another caveat of both this station, and that in the University of Washington, is that they were built with additional capacity as they pre-built an extension of the platform, which currently sits behind a temporary wall. 


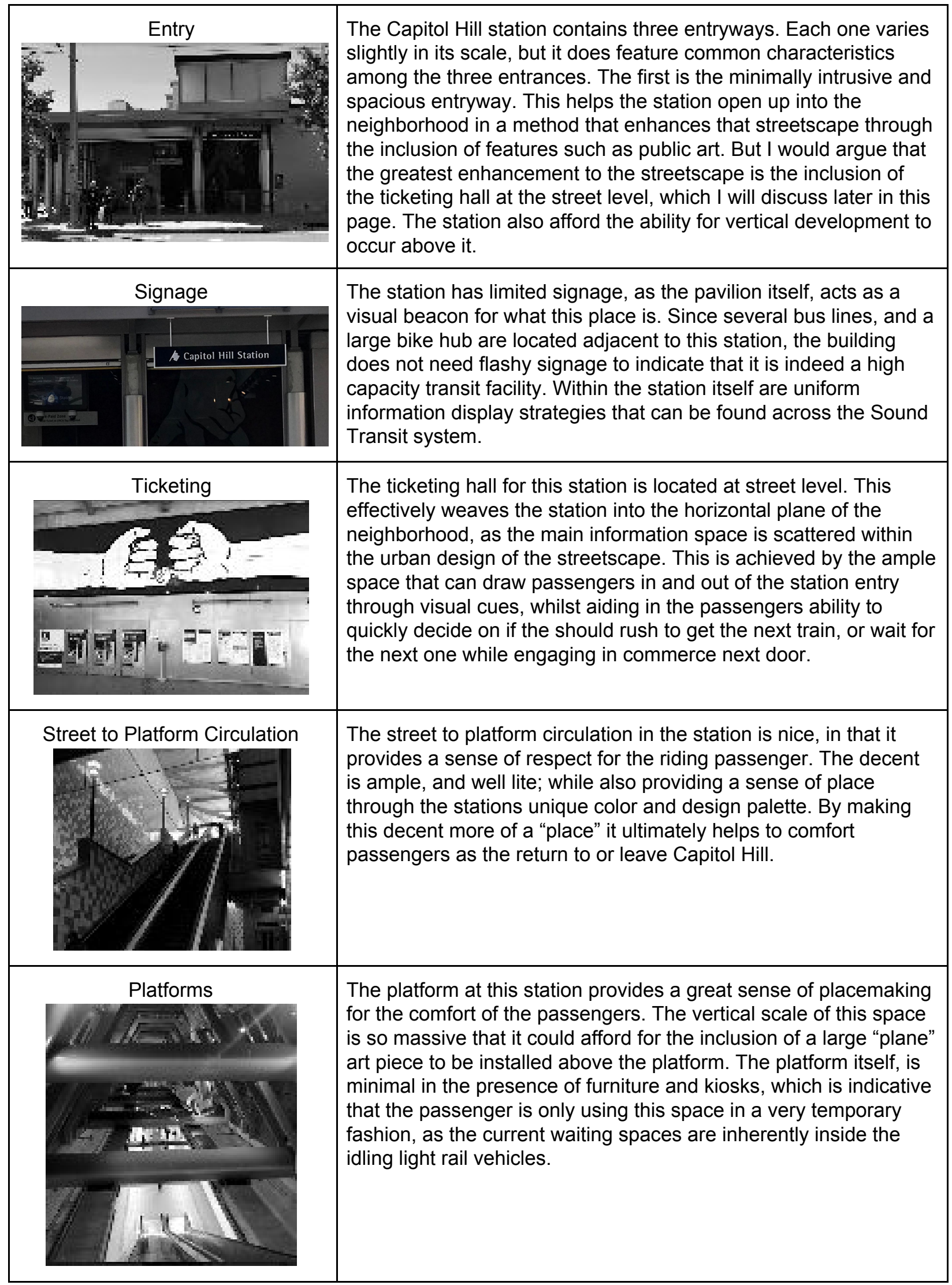




\section{University of Washington Station:}

The University of Washington Station is the current terminus of the Central Link Light rail line. The station opened alongside the Capital Hill Station in 2016. At the single entry point for this station sits a large pavilion that connects to other parts of the University campus via paths and bridges that branch from the station entry. The Entry pavilion contains the ticketing and visitor information space that leads passengers down a set of escalators. The descent down these escalators is unique for the Sound Transit system, in that the experience through this section is artistically distinct due to the installation of an art piece that has unique lighting conditions.

At the platform level sits a simple center running platform that has minimal furniture and decorative elements in comparison to the Capitol Hill Station. The platform level does not have the artistic touches found at the aforementioned station, as much of the artistic and architectural treatment of the station was saved for the entry and station circulation spaces. 


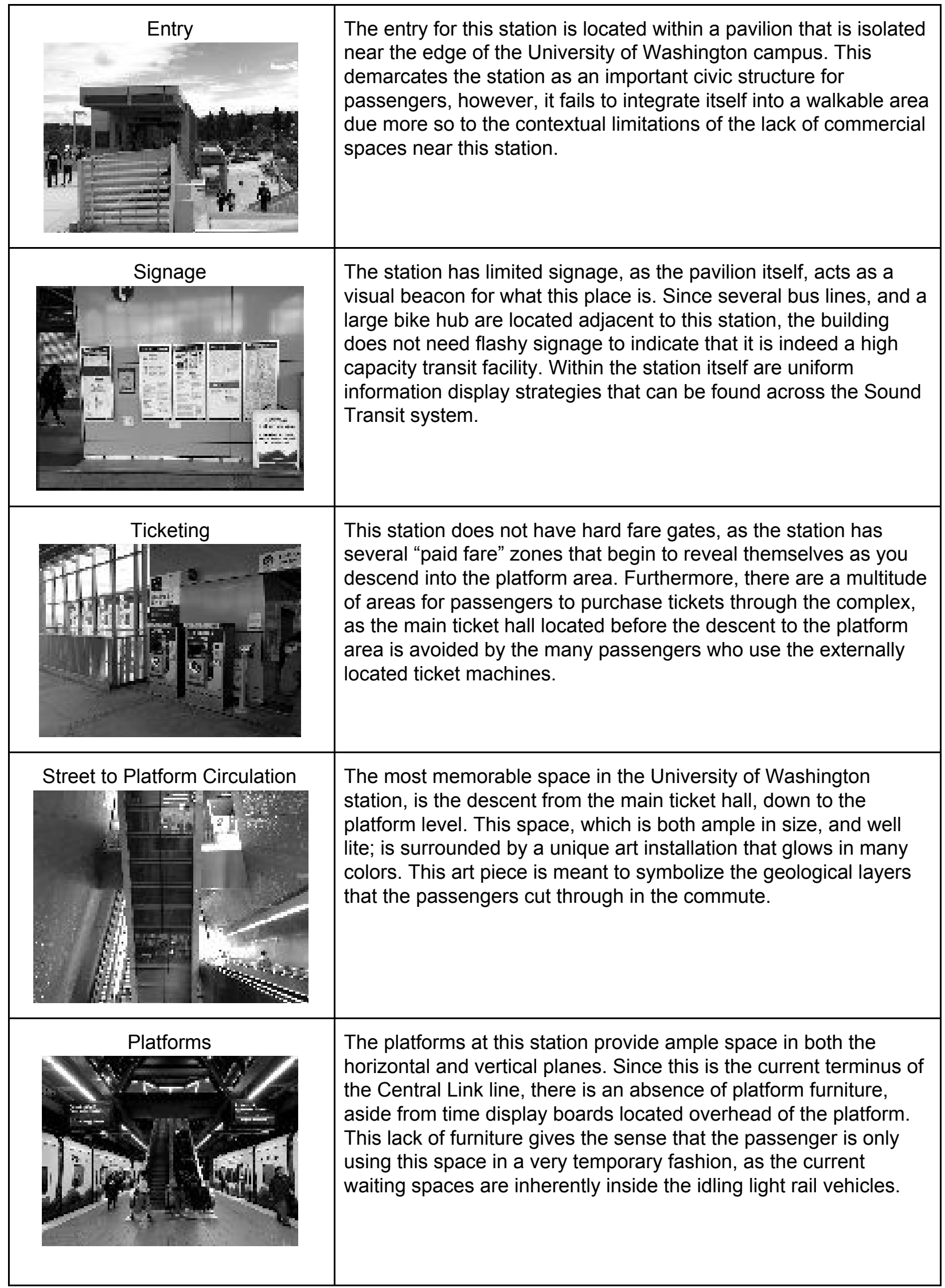




\section{Los Angeles Metro:}

Los Angeles Metro currently operates 4 rail lines that contain subterranean platforms. The agency is actively constructing three new underground stations as part of the new Crenshaw Line, it is nearing completion of a new regional connector project that is comprised of three new underground stations, and the agency is expanding its purple line subway line to the city of Westwood. This case study will observe a few of the existing stations for the underground heavy rail and light rail stations that the agency already has in operation, under construction, or in design; in order to assess commonalities in successful subterranean station design.

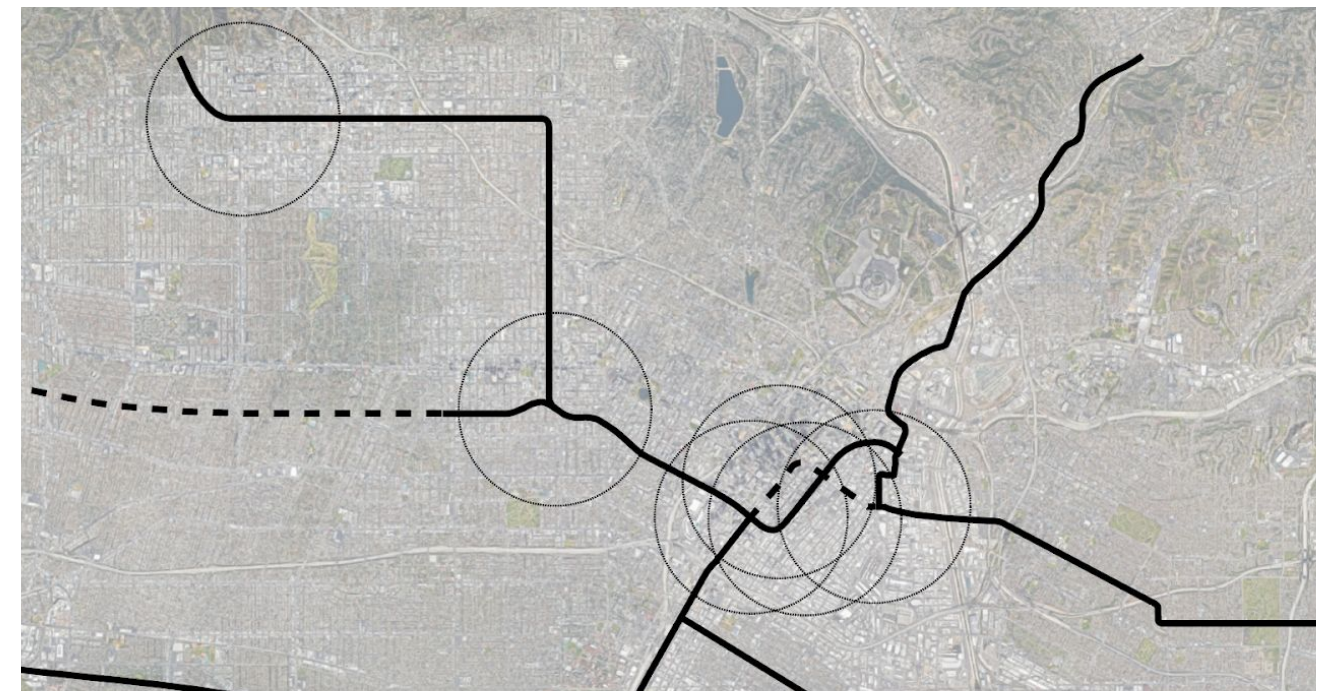

Image 7: an existing (solid), and planned or under construction (dashed) map of the Los Angeles Metro Rail system that I observed for this section of the study. The stations I have chosen are circled with dashed lines.

\section{7th Street/Metro Center Station:}

This was the first underground station constructed by Los Angeles Metro as part of the terminus of the Blue light rail line which opened in 1991. The station is currently served by four metro lines; the blue and expo light rail lines; and the red and purple 
subway lines. The station received an expansion in 1993 when the Red Line subway began service through the station.

The three platform station has three points of entry placed along 7 th avenue in downtown Los Angeles which vary in their external style. Each station entry portal directly responds to the building that surrounds the station. Each entry is nestled at the ground floor of the building, as it is surrounded by other ground floor spaces like retail storefronts and office building lobbies. An observation of mine though, is that the station integrates itself so well into the building that the entryway is located in, that I had a very difficult time finding the station entrance, as the signage was either minimal or nonexistent, or the station entry was only identifiable by small ticket machines located near the escalators that descend down into the station ticket hall.

Within the station are narrow walkways with low ceilings, which feed from a small ticketing space, and into circulation spaces that direct passengers down into the platform levels. Initial observation on my end, for this station are that sound is heavily projected in this space, causing uncomfortable hearing environments. Furthermore, the station has challenges with lighting; as much of the station is poorly lit amidst the cold concrete and metal encased station. Another issue is the confusing issues of circulation in this station. Since there is no unified lobby that connects all three entry points to the station, passengers are muddled with indiscreet signage that points passengers to the closest exit, rather than the exit that is closest to their destination.

However, as Los Angeles Metro's first underground station, it is understandable that this station was not built with a clear design intent; as the Metro Blue Line was built 
on a very stringent budget that required the agency to obtain used rail cars for the system's initial operation. Since the construction of this station, following Metro stations have improved their subterranean station design as I will explain in the following examples of the existing stations. 


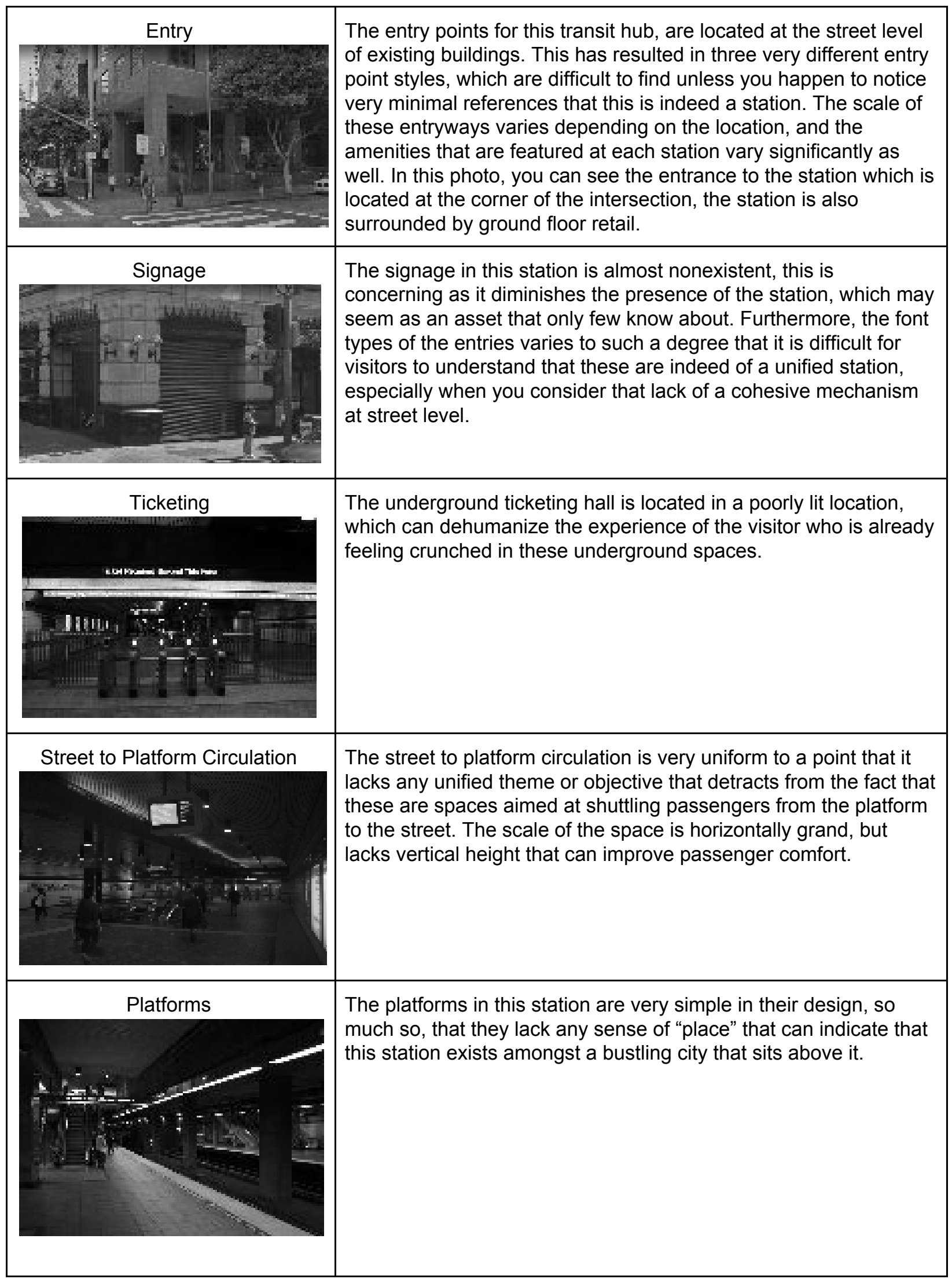




\section{Hollywood and Highland Station:}

The Hollywood and Highland Station was opened in 1992, when Metro Red Line began operations. The station sits at the center of the cultural heart of Hollywood Boulevard in Los Angeles. This station has a single entrypoint from Hollywood Boulevard, which leads passengers directly down into the ticketing hall of the station. The station itself is more architecturally distinct than those of Metro's purple lines and 7th and Metro Center Station due to unique art that was integrated into the stations more structurally beautiful interiors.

At the platform level, there are very high ceilings which minimize the need for direct light, as the platform has ample opportunities to shine light upwards, which can illuminate this otherwise cavernous environment. The high ceilings in this station also allow a more grandiose passenger experience, as the higher height of the interior of the station allows for a more relief of the feeling of compression that can be felt in the rail car and rail tunnels. 


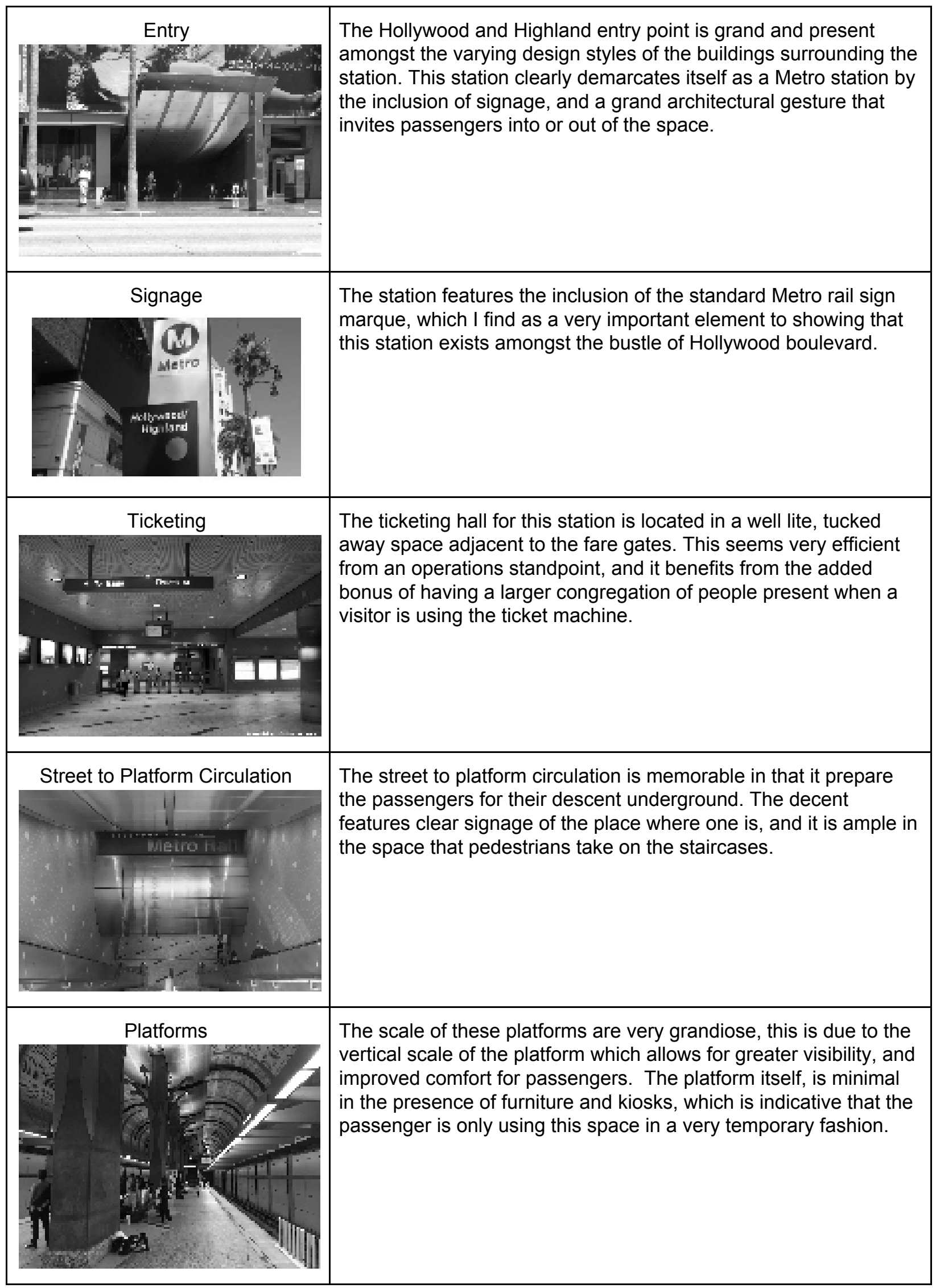




\section{Wilshire and Vermont Station:}

The Wilshire Vermont is a major transfer point between the two existing subway lines that Metro operates, these being the Red and Purple lines. The station has a unique layout in that the platforms are stacked one atop another, as the double decker single direction side platforms allow the trains to deviate in their own direction once trains go westward from the platform. When the station was first built, it was not fully completed, as the land that the station sits under had Transit Oriented Development Ambitions for Metro. This meant that the station was first opened with only a single entry point that was not very significant from an architectural standpoint.

After a 600-unit mixed use apartment project opened up atop the station, a second entryway was built and funded by the private developer. This new entry provided a more architecturally significant main entrance that was visually distinct from the building that it sat within. The station itself however, is very minimal and cold in its overall design, aside from a few visual art pieces plastered on columns in the platform level, there is no distinct placemaking as seen in other Metro Subway stations like the aforementioned Hollywood and Highland Station. 


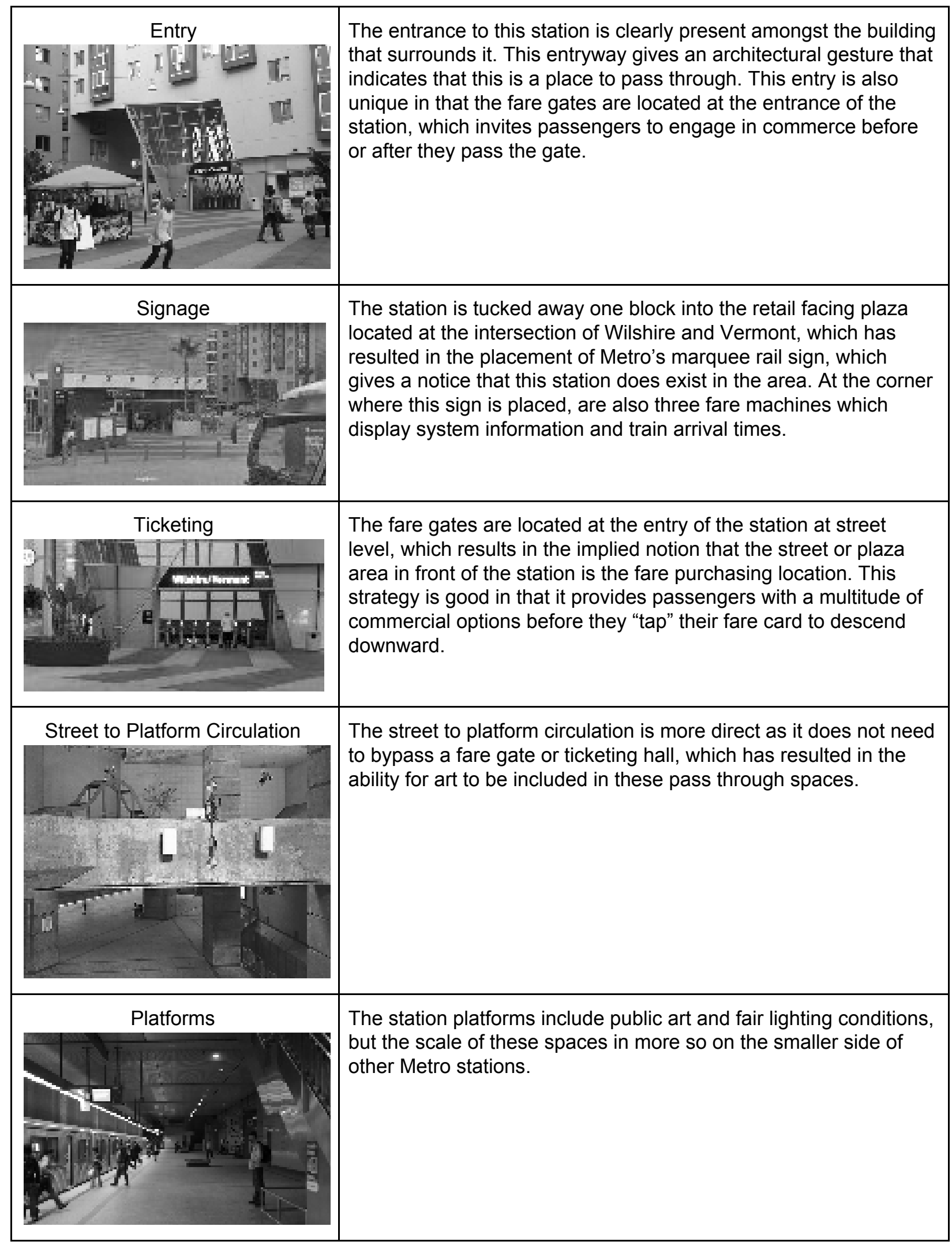




\section{Regional Connector Stations:}

The Regional Connector of Los Angeles is a project that aims to link Metro's Blue, Expo, and Gold lines via a new underground set of three interconnected stations. This project aims to provide more capacity in the downtown core, and it aims to improve transit connections across the greater Metro Rail coverage area. The three stations will be designed to accommodate the existing light rail fleet that Metro operates, which means that these stations will deviate in scale and operational usage than those of LA Metro's subway system.

The stations will share a similar design language that aims at streamlining the construction process and subsequent maintenance operations following the opening of the new stations in 2020 . The station entry points are primarily designed with minimal steel and heavy amounts of glazing that are aiming at providing more transparent station entry points. The interior of these stations also has streamlined designs that are aiming at having the direct benefits of project delivery as mentioned above. However, Metro does anticipate that their arts program will make meaningful placemaking opportunities in the three stations that will serve vastly different demographic and passenger type groups. 


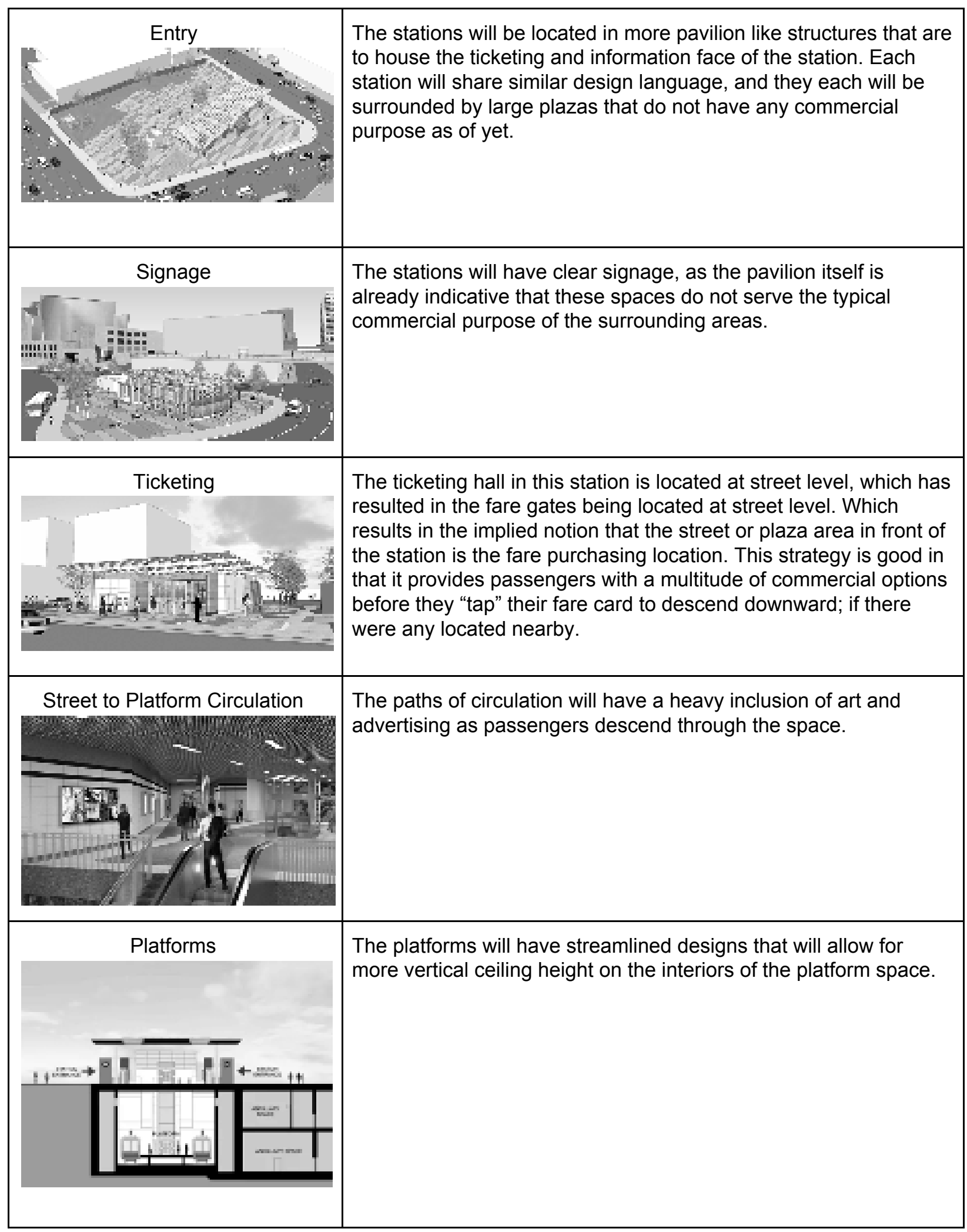




\section{San Francisco (BART \& MUNI):}

BART or Bay Area Rapid Transit, is a heavy rail driverless metro system that began operations in 1972. The system was first built with several above ground, and 10 below ground stations in the city of San Francisco and Oakland California. In this section of the paper, I will assess a few of these underground stations in order to discuss how the Bay Area copped with the introduction of underground spaces in the city. The stations that I will be assessing are the Embarcadero and Montgomery stations. These stations are the most utilized stations in the entire BART system, as they each serve upwards of 150,000 daily boardings. Each of these stations are also served by MUNI rail service, which is a light rail system run by the City of San Francisco.

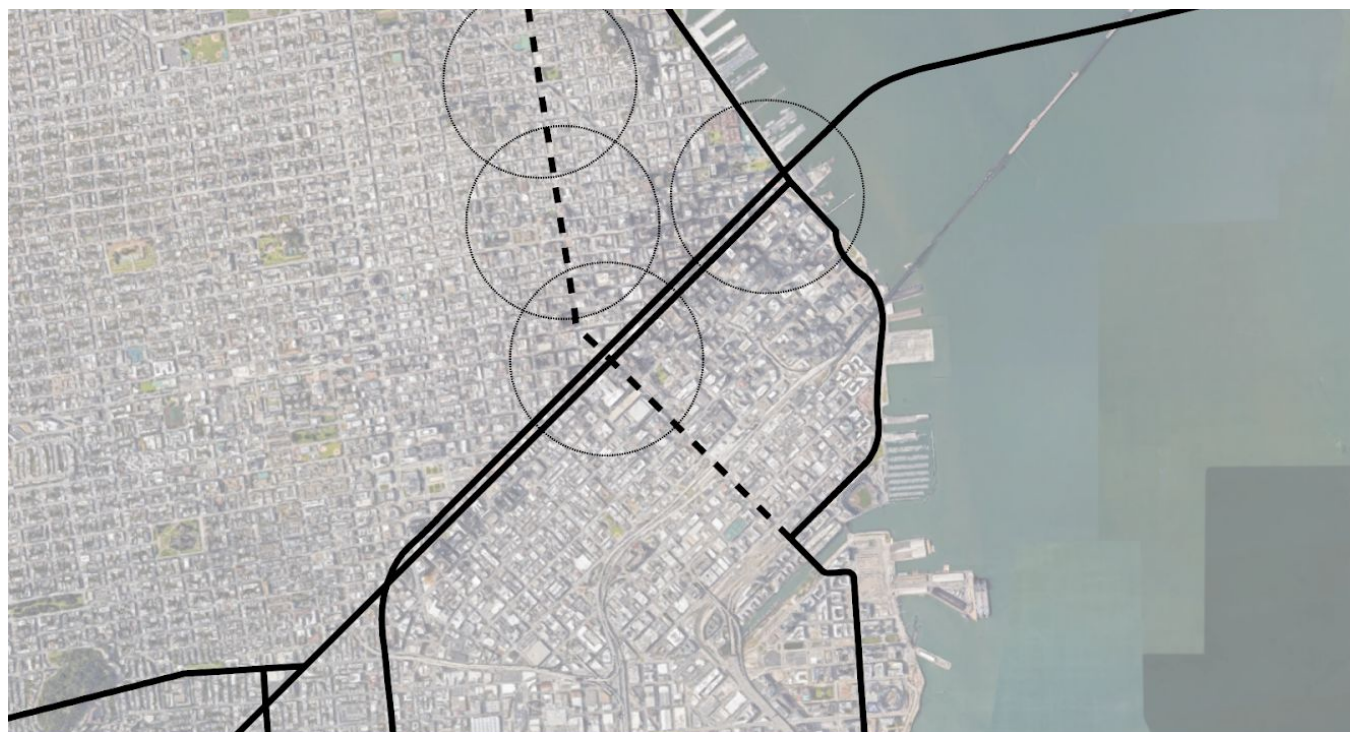

Image 8: an existing (solid), and planned or under construction (dashed) map of the BART and MUNI system that I observed for this section of the study. The stations I have chosen are circled with dashed lines.

Embarcadero Station is the first station in San Francisco that passengers access once they cross the transbay tube tunnel. This station is comprised of a double decker 
underground concourse that contains center running platforms for each direction of the respective rail system. This station has six entrance points from the street level which decent into a fully connected lobby space that has access to four ticketing gate points, MUNI, and BART respectively each have two ticketing entrance points.

The Entrances to the station lie amidst the enlarged sidewalks of Market Street, where simple signage and a staircase open down into the station below. The staircases that lead down are comprised of a single escalator descending upwards, and a rough;y six foot staircase that is navigable by both upward and downward travel. The entry portal itself is not covered by any canopy, which makes the station blend into the streetscape as there are no vertical obstructions in sight except for the BART and MUNI station sign. This means that the staircases are not weather protected, which can lead to maintenance problems with the escalator. The narrow staircase down into the station also possess a few accessibility issues during high passenger number times at the station. Embarcadero also only has one elevator that travels from the street to the station lobby, which can lead to issues with capacity and accessibility during downed elevator times.

The station lobby itself is located directly below the surface of Market Street, which is a central thoroughfare of the downtown core. This direct placement below the street has given the station fixed ceiling heights that I argue are too low for proper placemaking and human comfort during crowded station times. However, the direct placement of the station below the street helps the station to minimize the decent downward from street to lobby, and the subsequent lobby to platforms, which minimizes 
the amount of time that passengers need to enter and exit the station. The ticketing hall and lobby also lends itself with the blessing of having a unified space that does not require proof of fare; which can allow for passengers to find the most convenient station exit for them.

Due to the station having double decker center running platforms, the user experience at the platform level varies depending on which transit agency one is riding in the station. For MUNI passengers, the journey from the ticketing gate into the platform level is more grandiose and inviting than that of the BART platform. At the MUNI level, much of the platform has double the internal height of the Bart platform which allows for more opportunity for increased lighting opportunities and a minimization of the feeling of being in a compressed underground space.

The descent down into the BART level is double that of MUNI, and has to contend with the physical barriers that is passed when it cuts through the MUNI platform. Once at the platform level, the lighting in this area of the station is perceivably decreased as the low ceilings create a less inviting platform space than the MUNI platform. With this lower ceiling height also comes greater impacts to noise bouncing from the very loud train vehicles. 


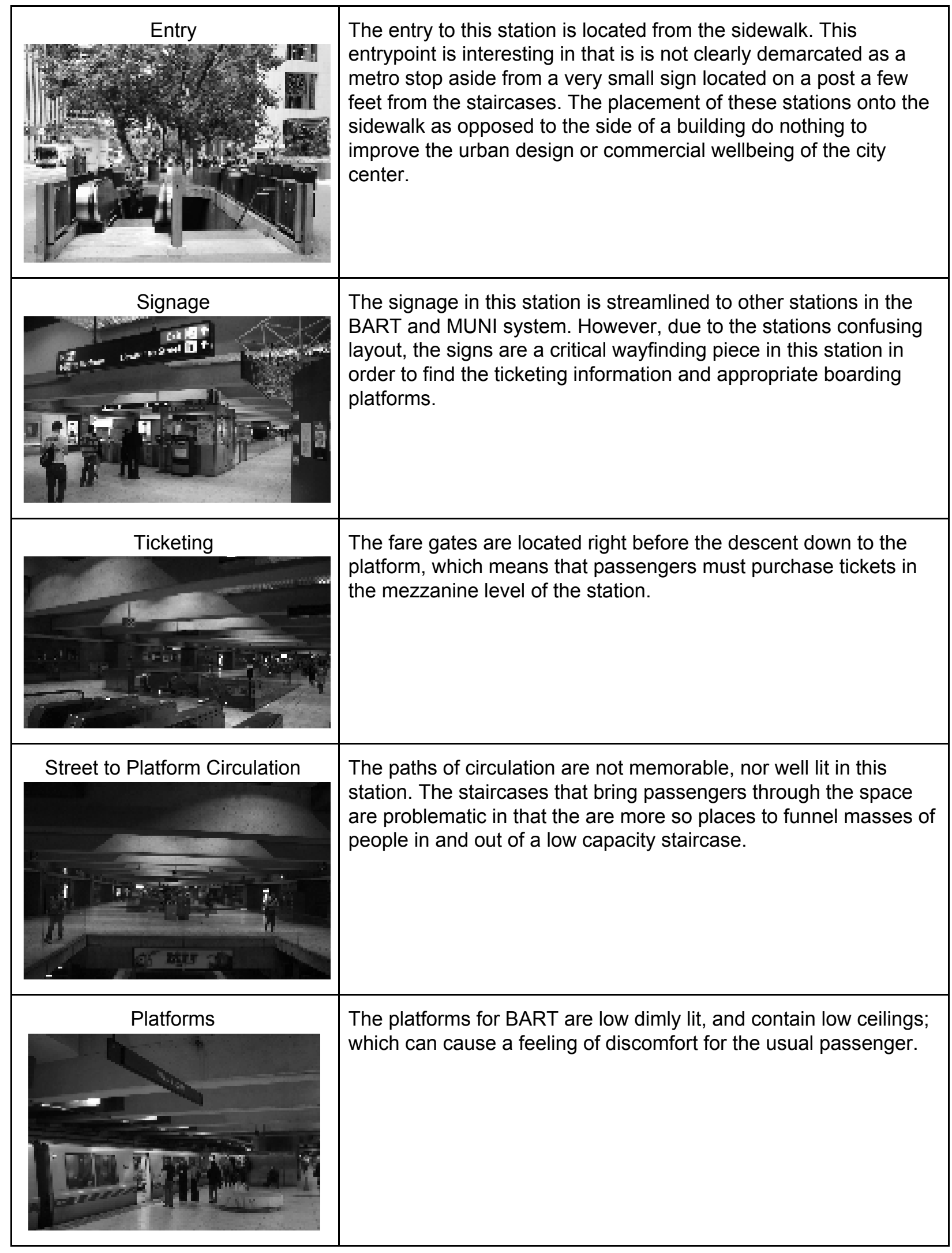




\section{Montgomery Station:}

This station is comprised of a double decker underground concourse that contains center running platforms for each direction of the respective rail system. This station has six entrance points from the street level which decent into a fully connected lobby space that has access to four ticketing gate points, MUNI, and BART respectively each have two ticketing entrance points.

The Entrances to the station lie amidst the enlarged sidewalks of Market Street, where simple signage and a staircase open down into the station below. The staircases that lead down are comprised of a single escalator descending upwards, and a rough;y six foot staircase that is navigable by both upward and downward travel. The entry portal itself is not covered by any canopy, which makes the station blend into the streetscape as there are no vertical obstructions in sight except for the BART and MUNI station sign. This means that the staircases are not weather protected, which can lead to maintenance problems with the escalator. The narrow staircase down into the station also possess a few accessibility issues during high passenger number times at the station. Embarcadero also only has one elevator that travels from the street to the station lobby, which can lead to issues with capacity and accessibility during downed elevator times.

The station lobby itself is located directly below the surface of Market Street, which is a central thoroughfare of the downtown core. This direct placement below the street has given the station fixed ceiling heights that I argue are too low for proper placemaking and human comfort during crowded station times. However, the direct 
placement of the station below the street helps the station to minimize the decent downward from street to lobby, and the subsequent lobby to platforms, which minimizes the amount of time that passengers need to enter and exit the station. The ticketing hall and lobby also lends itself with the blessing of having a unified space that does not require proof of fare; which can allow for passengers to find the most convenient station exit for them.

Due to the station having double decker center running platforms, the user experience at the platform level varies depending on which transit agency one is riding in the station. For MUNI passengers, the journey from the ticketing gate into the platform level is more grandiose and inviting than that of the BART platform. At the MUNI level, much of the platform has double the internal height of the Bart platform which allows for more opportunity for increased lighting opportunities and a minimization of the feeling of being in a compressed underground space.

The descent down into the BART level is double that of MUNI, and has to contend with the physical barriers that is passed when it cuts through the MUNI platform. Once at the platform level, the lighting in this area of the station is perceivably decreased as the low ceilings create a less inviting platform space than the MUNI platform. With this lower ceiling height also comes greater impacts to noise bouncing from the very loud train vehicles. 


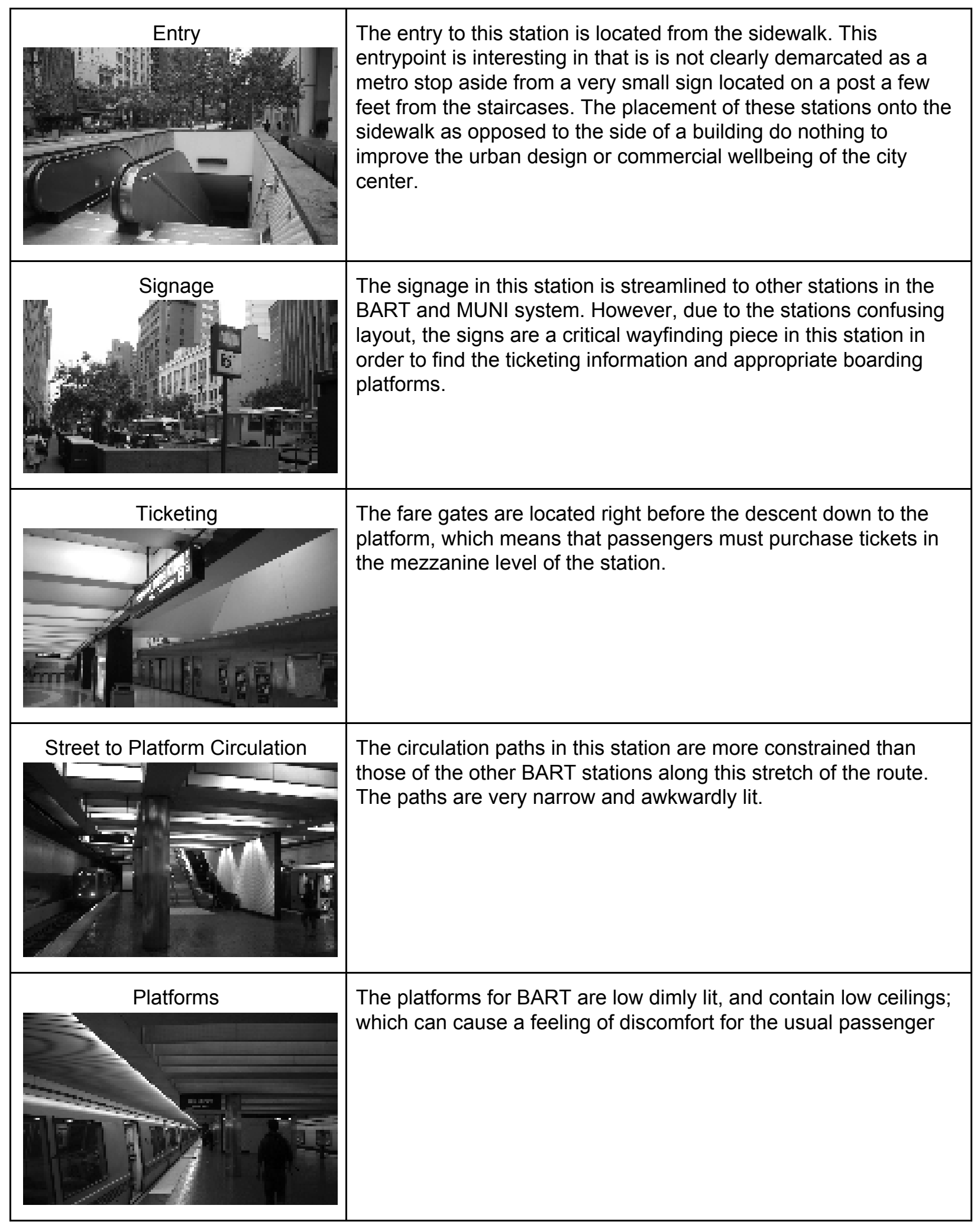




\section{Station Location:}

The proposed alignment for this light rail tunnel, and its subsequent stations are currently under review by TriMet, METRO, and the City of Portland. However, the assumed full tunnel alignment is anticipated to have stations at; Lloyd Center, Rose Quarter Transit Center, Union Station, Pioneer Square, Portland State University, and the West End of Downtown Portland.

The station locations are intended to retain existing ridership trends within fewer amount of stations. The stations are also intended to attract higher ridership, as the systems higher capacity of service and faster travel times will ensure a reliable and rapid connection through and within the downtown core. The exact placement of these stations will vary depending on several conditions that relate to land acquisition, and geological conditions which may result in rail platforms being located far from the station entries at street level.

Each station will also need to accommodate higher amounts of passengers as the initial investment in these underground platforms may increase the service area of the station from the TriMet standard of the current one quarter mile, to a catchment area of half a mile for each station entry.

Considering these factors, I believe the station location may be not as relatively important as the entry points to the station itself. It is important that the stations have at least two points of entry in order to ensure that passengers can move freely and easily to the exit closest to their destination. But, it is also important that these entry points exhibit the following characteristics that I will elaborate on later in this paper. 


\section{Station Entry:}

Current MAX station conditions in downtown Portland contain a blending of platforms into the urban layout of Downtown Portland. However, having platform be located below ground, beyond a station entry portal requires TriMet to rethink how these stations will best serve the commercial and public spaces of Downtown.

When designing a station entry, it will be crucial to ensure that signage play an important role in the demarcation of the new transit zone. The portal should also be of ample size in order to accommodate large passengers flows in an attractive and welcoming entryway.

The entry point should ensure that, even if the architectural language of the entry varies, that there are clear signage standards that can aid in establishing that these are stations. The entry points should seek to include themselves amongst the store fronts of the city, in order to make sure that the blending of transit and retail continue to be achieved. The most relevant example of this is the Wilshire and Vermont station, which is pictured below.

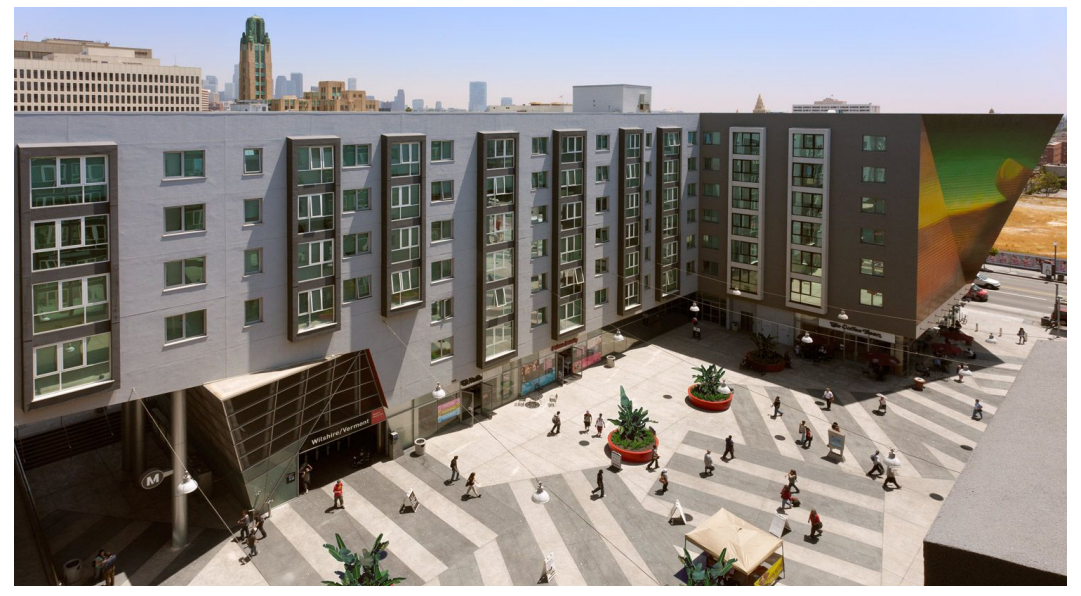

Image 9: Wilshire and Vermont station and the development that surrounds it. Image by Los Angeles Metro. 


\section{Ticketing Hall:}

Current ticketing strategies for the MAX system consist of ticket machines at the platform, however more recently, TriMet has been pushing towards "paid-fare zone" which require passengers to obtain proof of payment before they enter into these visually demarcated zones. The "paid-fare zones" have caused a lot of controversy for TriMet in recent years, a fare evasion on light rail trains has been difficult for TriMet to manage due to recent regulatory restrictions and the systems lack of proper ticketing turnstiles.

The underground platforms will allow TriMet the opportunity to create new entry lobby spaces that provide access to fare purchases and HOP card reloading stations in an area that is not at the platform space. These spaces also provide the agency with the opportunity to provide more formal customer information spaces that help to aid and inform new and current passengers.

It is important that TriMet assess the feasibility of having a ticketing dispensing location that is located before possible implementation of ticketing turnstiles that can manage proper fare collection into the platform area. The ticketing turnstiles could also provide TriMet with additional information on ridership data if the tapping of a fare card is to be utilized at the exit of the fare zone as well.

My design suggestion for the agency, is to include ticketing and visitor information at the street level, before the descent down into the platform level. This will do a few things to maintain the current success' of light rail in downtown Portland. First, the placement of these at street level will allow for a more active streetscape for 
passengers who want to buy tickets and learn about the system. This added benefit of having the information and amenities at street level results in the implied notion that the street or plaza area in front of the station is the fare purchasing location. This strategy is good in that it provides passengers with a multitude of commercial options before they "tap" their fare card to descend downward. An example of this is at the Capitol Hill station in Seattle. Where the ticket information is located at the entrance of the station.

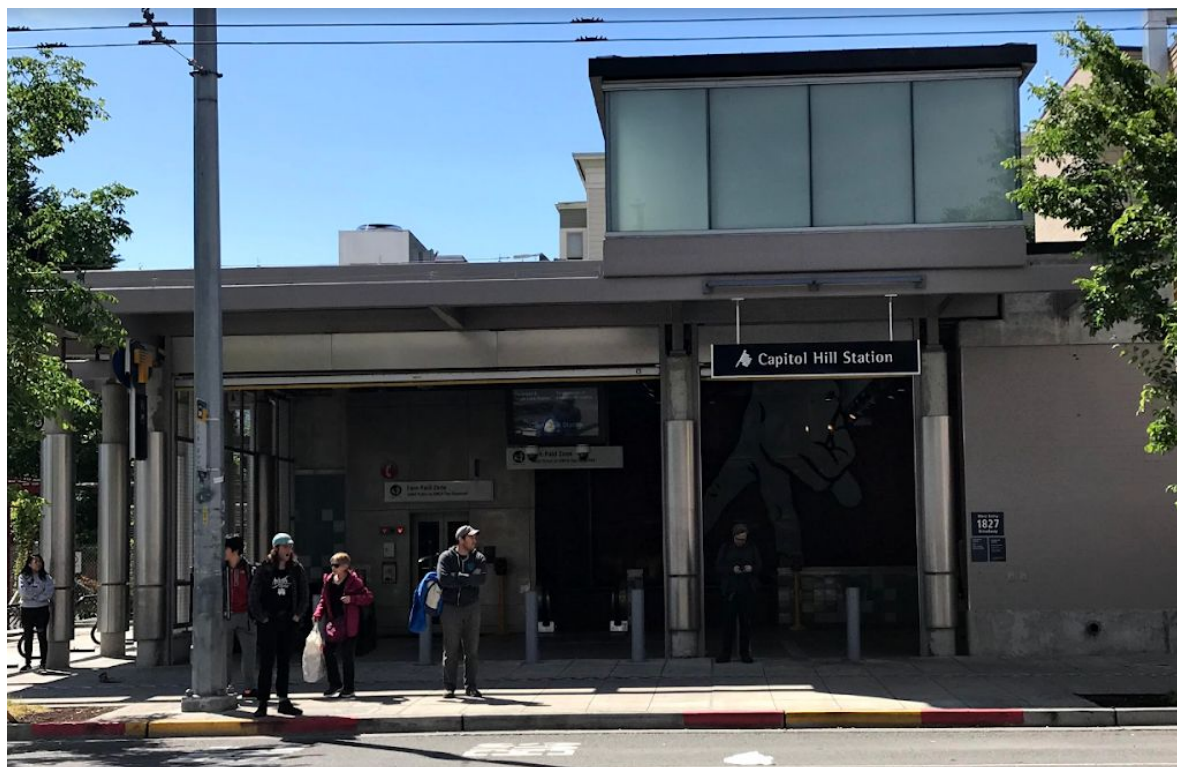

Image 10: Capitol Hill Station entrance. Photo by Antonio Crosier.

\section{Street to Platform Circulation:}

Existing platform conditions currently exist in two typologies for TriMet, these are primarily the island platform that is detached from the sidewalk, the second being the stations found in Portland's inner core, where stations front the entire edge of the sidewalk.

The first platform type has limited points of entry for the platform, where passengers are funneled in via one of two access points that are at the end of the 
platform. The entry is also where ticketing information and machines are dispensed before the passengers access the "paid fare zone" of the station. The second station type, which are located at the sidewalk edge, do not seem to have any direct entry point, as the platform lies directly in contact with the entire edge of the platform. These platforms types are difficult to control from an operational standpoint, as the station blends into the urban streetscape in an effortless manor. As such, these platform types, which are only located in downtown Portland, have become an important piece of the streetscape of the inner city. The platforms information, ticketing, and shelters are delicately tucked near the edges of the sidewalk as demarcation points for the light rail station.

Because the public has grown to know only these two types of platforms, which are always accessible via a sidewalk or by crossing a street or public path, it is important that TriMet and the City of Portland uncover and seek the best solution for how to integrate the underground stations into Portland's City Center. The Platforms play such a critical role in the urban streetscape, that their absence will shift how visitors and passengers alike interact with transit and business in Portland.

Station entrance points, should be clearly demarcated, these can help provide ease of access for passengers searching for their station, while the new underground system could have the added benefit of attracting new ridership from curious passersby. Each entrypoint should also ensure that it is accessible to all people of differing mobility conditions, as a problem with many underground platforms is that they often times only 
have a singular point of entry for those with mobility issues, granted there's even an accessible entrance in place for them to begin with.

A decision that TriMet and regional planners need to make however, is does each state has its own unique design? Or will the underground stations of the regional connector have different design styles that relate more to their contexts? If the latter were to be the case, it is assumed that the station entry points can deviate in style so much so that the agency will need to find a medium that can create clarity in how each station entry is part of the same system.

The link from street/ticketing lobby to the platform itself should be seen as an opportunity for providing passengers with a respectful well design space that contains proper lighting, wayfinding opportunities, and a minimization of visual clutter as being in a cavernous environment may already prove difficult for passengers to navigate. An example of a beautiful circulation path is that of the University of Washington station, which provides an art installation that can be seen from all vertical modes of circulation.

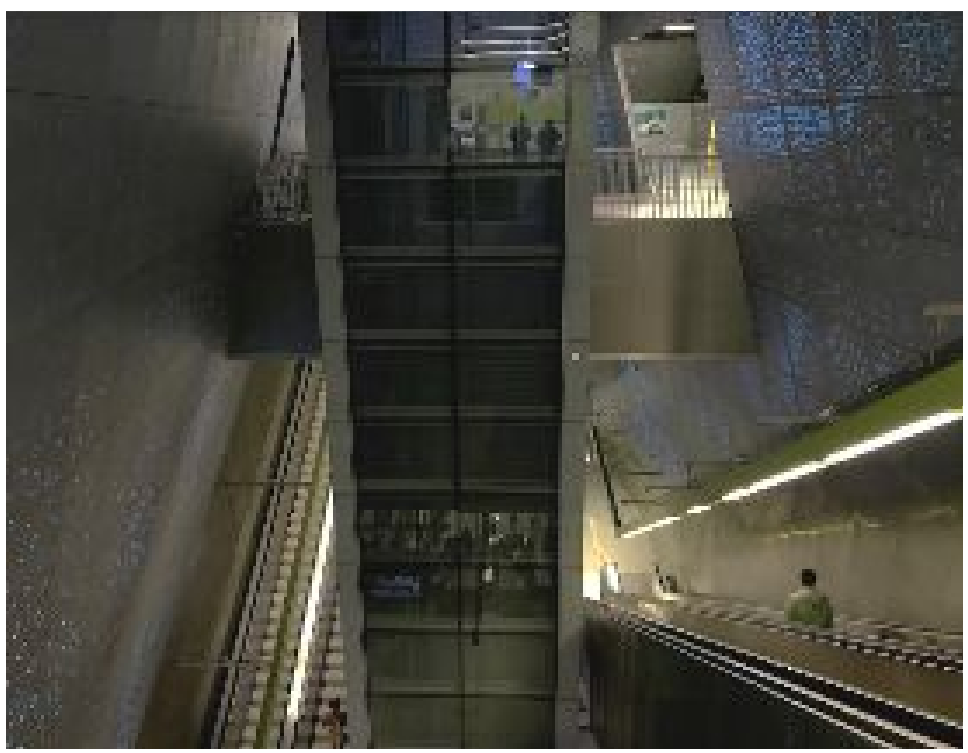

Image 11: University of Washington Link light rail ticket hall to platform circulation space. Photo by Antonio Crosier. 
Positive experiences in vertical circulation within the station itself can be a cumbersome effort amidst constrained budgeting issues and lack of space. In the University of Washington station, Sound Transit decided to design the descent down to the platform in a very artistic way. The agency worked in partnership with and artist to design an art installation that had unique lighting patterns that symbolized the topography that the passengers were travelling down into.

This street to platform circulation should also anticipate ridership growth, which means that the planners should ensure that there is enough vertical circulation opportunities for the station to absorb possible surges in passengers growth. I point this out as a critical piece due to existing stations that I have discussed earlier in this paper, that are experiencing critical levels of congestion within their underground stations. In the Embarcadero station for BART, the station has amassed a surge in the number of passengers in the station; which has resulted in severe passenger congestion at not only the platform level, but also of the vertical circulation points throughout the station complex. This extreme congestion has led BART to spearhead an effort to create additional platforms and vertical access points within the underground complex.

\section{Platform Design:}

The platform design itself will do little to enhance the economic vitality and walkability of the city center, but this does provide the opportunity to provide a greater impact on passenger comfort. Since the stations are located underground, the perception of time and space relative to the city will be blurred obscured in the underground realm. These challengers ultimately provide the platforms with the 
opportunity to have a design that can establish the station as part of a place. An example of this can be seen in the Hollywood and Highland station, which has a generously high platform space that includes an intricately designed interior. The platform itself has simple art installations and good lighting features which help to enhance the underground environment.

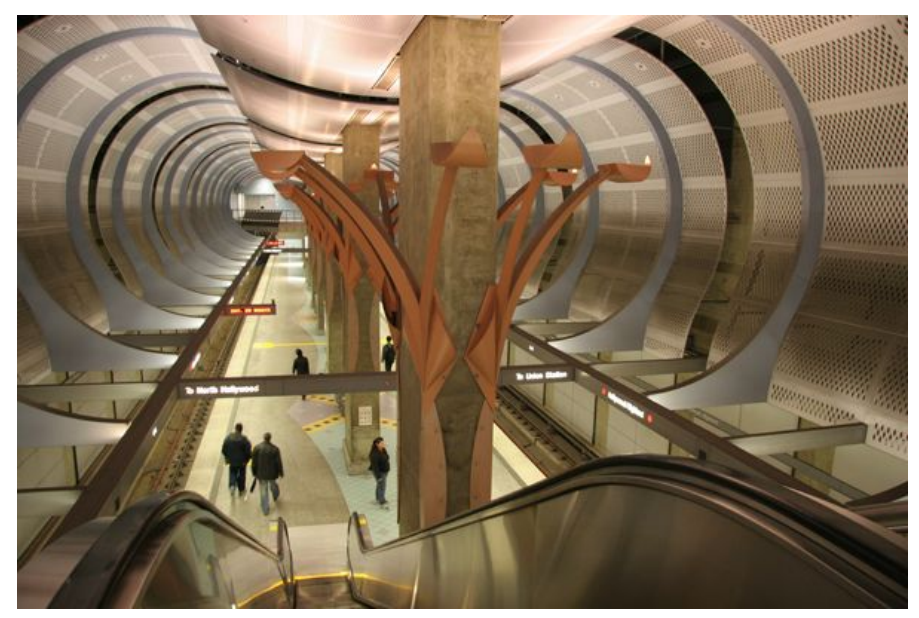

Image 12: Platform space of the Hollywood and Highland station, this interior space has a unique interior design in comparison to the rest of the LA Metro system. The design and improves passenger comfort with the inclusion of public art, good lighting, and ample space for visibility. Image by LA Metro.

In conclusion, the platforms will not have the same adverse effect on the urban design of the city of Portland's streets, but it does provide the region with the opportunity to make these stations an extension of place-making strategies for the areas that the station will serve.

\section{Conclusion:}

In this paper, I decimated case studies on exiting and under construction, subterrenean stations in order to create a comprehensive guide for how TriMet and the City of Portland could design the Regional Connector Tunnel under Downtown Portland. 
As such, I attempted to outline the positive and negative aspects of underground stations, in order to distinguish the importance of planning proper underground spaces in a city that is only used to surface street activity.

My conclusions for this uncovered that the economic vitality and walkability of the City Center will be adversely affected by the impact of moving MAX stations underground. This meant that I sought to find out how to minimize the impacts of the infrastructural shift of the MAX system. The first topic the agency should look into is how to integrate ticketing and information at the street level, adjacent to the station entry points. This will go a long way in ensuring that passengers and passersby alike, can adjust transport plans as needed in areas that contain high amounts of commercial and civic activity. The design of these spaces does not need to adhere to a single "design language" across the downtown tunnel system, but only under the conditions that uniform signage techniques are adopted across the entry areas of the new stations.

The circulation from street to platform, and the subsequent platform design itself now provide the agency and city to bring about design techniques that improve passenger comfort while also creating more place based design strategies at each station. The inclusion of artistic installations, larger scale circulation spaces and platform areas, and minimization of barriers in paths of egress can aid in improving future underground station design for the Portland region.

Ultimately, the stations will provide the city with not only a challenge, but with an opportunity to create higher capacity transit for the rapidly growing region which can help to foster the continued sense of walkability, economic vitality, and the improvement 
of passenger comfort in the underground stations themselves. The shift from surface running to underground environments will prove to be challenging for a city that has such an active streetscape, however other cities have proven many tested and tried elements of how to create dynamic underground transit stations that serve and enhance their communities. 


\section{Annotated Bibliography}

Moreno, Pérez, Reche, Martins, De Miguel, Capdevila, Centelles, Minguillón, Amato, Alastuey, Querol, and Gibbons. "Subway Platform Air Quality: Assessing the Influences of Tunnel Ventilation, Train Piston Effect and Station Design." Atmospheric Environment 92 (2014): 461-68.

Through the use of scientific analysis of collected data of various subterranean stations in Barcelona. Here, the station design and its air circulation systems are compared to show the most effective methods for passive station ventilation strategies that continue to promote passenger comfort. This article contains data, tables, and diagrams of different tunnel portal and platform typologies in Barcelona.

Shah, Ravi R., Jonathan J. Suen, Ilana P. Cellum, Jaclyn B. Spitzer, and Anil K. Lalwani. "The Influence of Subway Station Design on Noise Levels." Laryngoscope 127, no. 5 (2017): 1169-174.

This article observes the effects of noise levels on humans in 20 New York City Subway stations. Noise level data was observed in two sets of categories; curved and straight, platforms; who's noise levels were measured at each end, and in the center of each platform. The distinction of straight versus curved platforms was done by visual means. In all, the data that was observed noted the different noise profiles that each platform type exhibits in a given location along the station area.

Leung, and Lee. "Estimation of Electrical Power Consumption in Subway Station Design by Intelligent Approach." Applied Energy 101, no. C (2013): 634-43.

The collection of energy information in Hong Kong's MTR subway stations was approached in order to develop a better understanding of energy consumption patterns in subterranean stations. Computer based simulation tools were utilized to alter the electrical patterns that were observed in order to identify areas for energy conservation and efficiency. It must be noted that certain electrical uses by objects such as elevators were not included in this due to the absence of electrical collection data. 
Wicker, Robert. The Architectural Development of the Subway Station Key Architectural Considerations in Subway Station Design as Observed in Twenty Selected European and North American Systems, 1980, ProQuest Dissertations and Theses.

This thesis demarcates the architectural significance of subway station designs from London's first underground station, to contemporary stations such as those of BART (Bay Area Rapid Transit). The development and evolution of how the design of subway stations are designed is approached through the analysis of ground level and elevated concourses that predate underground stations.

Li, Hibino, Koyama, and Zheng. "Tailoring Map Design Based on Map-Reading and Wayfinding Behaviour in Subway Stations." Procedia - Social and Behavioral Sciences 42, no. C (2012): 466-76.

This article observes and denotations the differing station layout map designs in Seoul South Korea through the comparison of two and three dimensional maps. The study begins by having participants find their way out of a subterranean station without any reference map, followed by the use of two or three dimensional maps to aid passengers. In all, the article observes how the maps are interpreted by passengers.

Han, Kwon, and Chun. "Indoor Environment and Passengers' Comfort in Subway Stations in Seoul." Building and Environment 104 (2016): 221-31.

Three transfer stations with two platforms (six-stations total) in Seoul South Korea were studied through three seasons to observe the passenger comfort levels in relation to air quality, temperature, and humidity among other factors. The study seeked to uncover parallels between each differing station in order to understand how the stations performances vary or are similar among the general public. The study looked beyond thermal comfort, to decimate conclusions on the performance of each station based on research that identified human comfort levels.

Assimakopoulos, and Katavoutas. "Thermal Comfort Conditions at the Platforms of the Athens Metro." Procedia Engineering 180 (2017): 925-31. 
This article discusses that data collected of the Athens Metro thermal performance as it related to human comfort. The data monitored included air temperature, humidity, wind velocity, and air quality, among other factors. This was then assessed and scored on each stations performance as it relates to predetermined levels of human comfort in varying seasonal conditions.

John Zacharias, Tianxin Zhang, and Naoto Nakajima. "Tokyo Station City: The Railway Station as Urban Place." URBAN DESIGN International 16, no. 4 (2011): 242-251.

This article disseminates the changing use of Tokyo Station, which lies in the center of Tokyo. The stations transformation from transfer point to urban destination is denoted through the historical background and present day changes at the concourse. The transformation has led to a commercial renaissance in the station complex that has led to the various commercial and transit groups to partner in creating a new social space that is to be enjoyed by current and prospective passengers. 